\title{
Native Cellulose Microfiber-Based Hybrid Piezoelectric Generator for Mechanical Energy Harvesting Utility
}

\author{
Md. Mehebub Alam and Dipankar Mandal* \\ Organic Nano-Piezoelectric Device Laboratory, Department of Physics, Jadavpur University, \\ Kolkata 700032, India. \\ Corresponding author. Tel.: +91 332414 6666x2880; Fax: +91 332413 8917; E-mail: \\ dipankar@phys.jdvu.ac.in
}

HPG fabrication. Schematic representation of the fabrication process of the flexible hybrid piezoelectric generator (HPG) is shown in Figure S1. The preparation is described as follows: firstly, cellulose microfiber with MWCNTs is dispersed in PDMS by mechanical agitation on the basis of a mass ratio of cellulose-MWCNTs-PDMS =5: 0.5: 100 as shown in Figure S1ab. Then mixed solution was poured into petridish like Al-foil mold (Figure S1c). After removal of the bubbles from the solution with the help of a vacuum pump, it was dried at $80^{\circ}$ C for $30 \mathrm{~m}$ to convert it from solution to a round shaped composite film. 
(a)

(b)

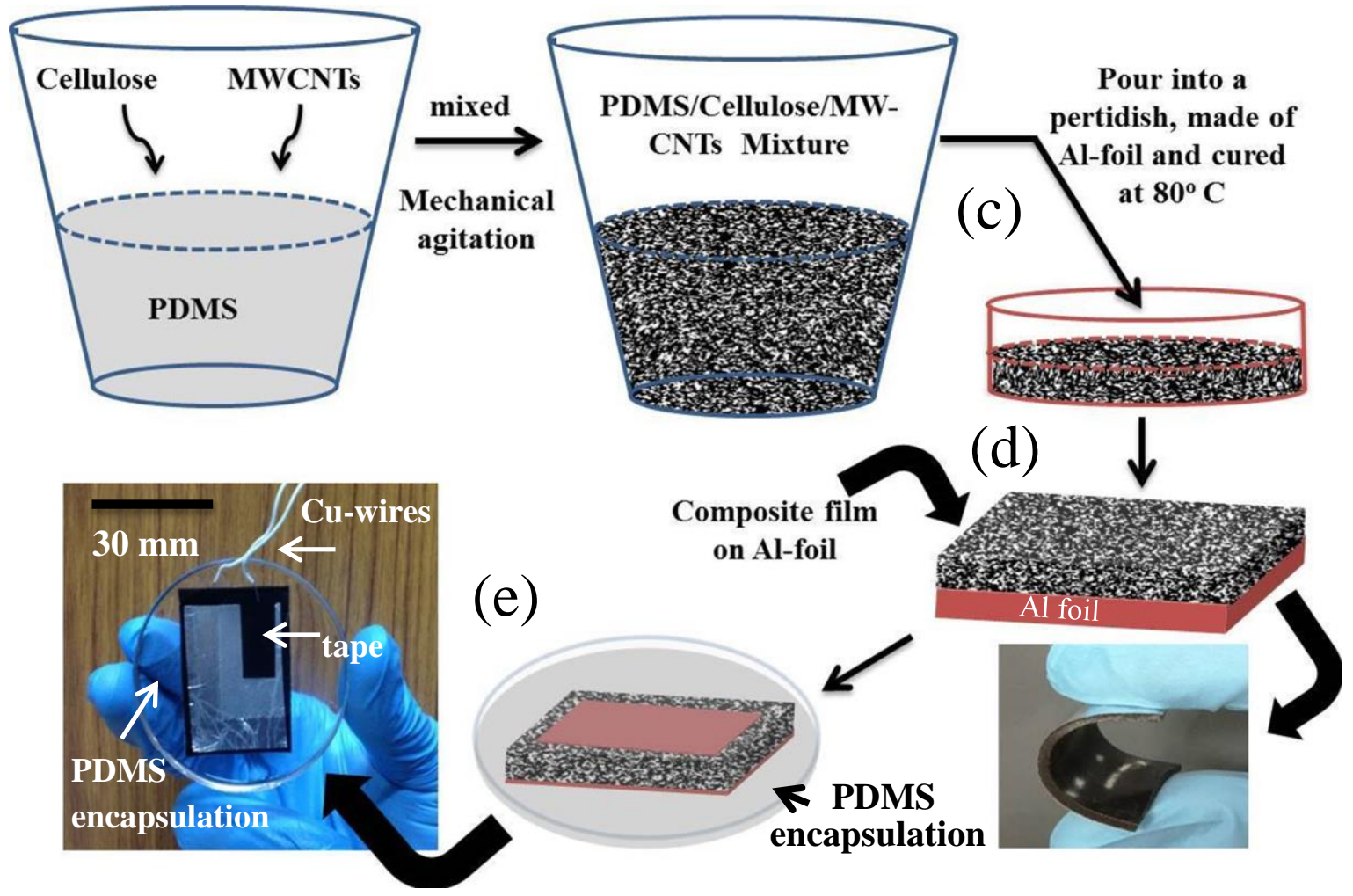

Figure S1. The schematic of HPG fabrication process. (a)- (b) cellulose and MWCNTs are dispersed in PDMS by mechanical agitation in the mass ratio of 5:0.5:100. (c) PDMScellulose-MWCNTs mixture was poured into an Al-foil mold petridish and subsequently dried to get a composite film. (d) The composites film, after cutting into a rectangular shape (including the Al-foil at the bottom). The real image of the composite film including the Alfoil underneath is shown at bending state, demonstrating its flexibility. (e) Another Al-foil $\left(33 \times 25 \mathrm{~mm}^{2}\right)$ is attached to the top surface to serve as an electrode and the entire electrodecomposite-electrode structure is covered with a thin pure PDMS layer to protect from direct hitting. The digital photograph of the HPG is also shown. 
Flexible composite film attached with Al-foil (act as a bottom electrode) then cut into a rectangular shape of $40 \mathrm{~mm}$ of length, $28 \mathrm{~mm}$ of width and $2 \mathrm{~mm}$ of thickness as shown in the upper image of Figure S1d. The real image of the composite film on the Al-foil, demonstrating its flexibility, is also illustrated from lower image of Figure S1d. Another Alfoil $\left(33 \times 25 \mathrm{~mm}^{2}\right)$ is physically attached to the upper surface that served as a top electrode. $\mathrm{Cu}$ wires were then soldered with Al-electrodes and covered with conducting carbon tape. This sandwich like hybrid piezoelectric generator (HPG) finally encapsulated by pure PDMS layer to protect the HPG from direct hitting (Figure S1e, right side). The digital photograph of the fabricated HPG in the final form is depicted in Figure S1e (left side). 
Table S1: Vibrational band assignments of cellulose I revealed from FT-IR spectra, shown in inset of Figure S2. ${ }^{\text {S1-S4 }}$

\section{Wavenumber $\left(\mathrm{cm}^{-1}\right) \quad$ Band Assignment}

897

1031

1055

1110

1161

1204

1281

1315

1335

1370

1428

2900

3340
COC asymmetric stretching

$\mathrm{CO}$ at $\mathrm{C}-6$ stretching

CO stretching vibrations

Asymmetric vibration of glucose ring

COC asymmetric vibration

$\mathrm{COH}$ in-plane at $\mathrm{C}-6$ bending

$\mathrm{CH}$ and $\mathrm{OH}$ vibration

$\mathrm{COH}$ and $\mathrm{HCC}$ vibration

$\mathrm{OH}$ and $\mathrm{CH}_{2}$ vibration

intermolecular hydrogen bond bending

$\mathrm{CH}_{2}$ vibration; $\mathrm{HCH}$ and $\mathrm{OCH}$ in plane banding;

$\mathrm{CH}$ and $\mathrm{CH}_{2}$ vibration presence in aliphatic methylene

$$
\text { groups }
$$

Stretching vibrations of $\mathrm{CH}$ and $\mathrm{OH}$ groups 
Text S1. Pressure calculation. ${ }^{\text {S5, S6 }}$

We can calculate the input pressure on the HPG from the following equations,

$$
\begin{aligned}
& \mathrm{m} \cdot \mathrm{g} \cdot \mathrm{h}=\frac{1}{2} \mathrm{mv^{2 }} \\
& (\mathrm{F}-\mathrm{m} \cdot \mathrm{g}) \cdot \Delta \mathrm{t}=\mathrm{m} \cdot \mathrm{v} \\
& \sigma=\frac{\mathrm{F}}{\mathrm{S}}
\end{aligned}
$$

Here, $\mathrm{m}=2.16 \mathrm{~kg}$ is measured by using a laboratory balance, $\mathrm{g}=9.8 \mathrm{~N} / \mathrm{kg}, \mathrm{h}=0.05 \mathrm{~m}, \Delta \mathrm{t}=$ $0.182 \mathrm{sec}$ is the estimated average time variation between the two consecutive voltage peaks and $\mathrm{S}=825 \mathrm{~mm}^{2}$ is the effective electrode area of the HPG,

Therefore, input force, $\mathrm{F} \sim 33 \mathrm{~N}$ and applied stress, $\sigma \sim 40 \mathrm{kPa}$.
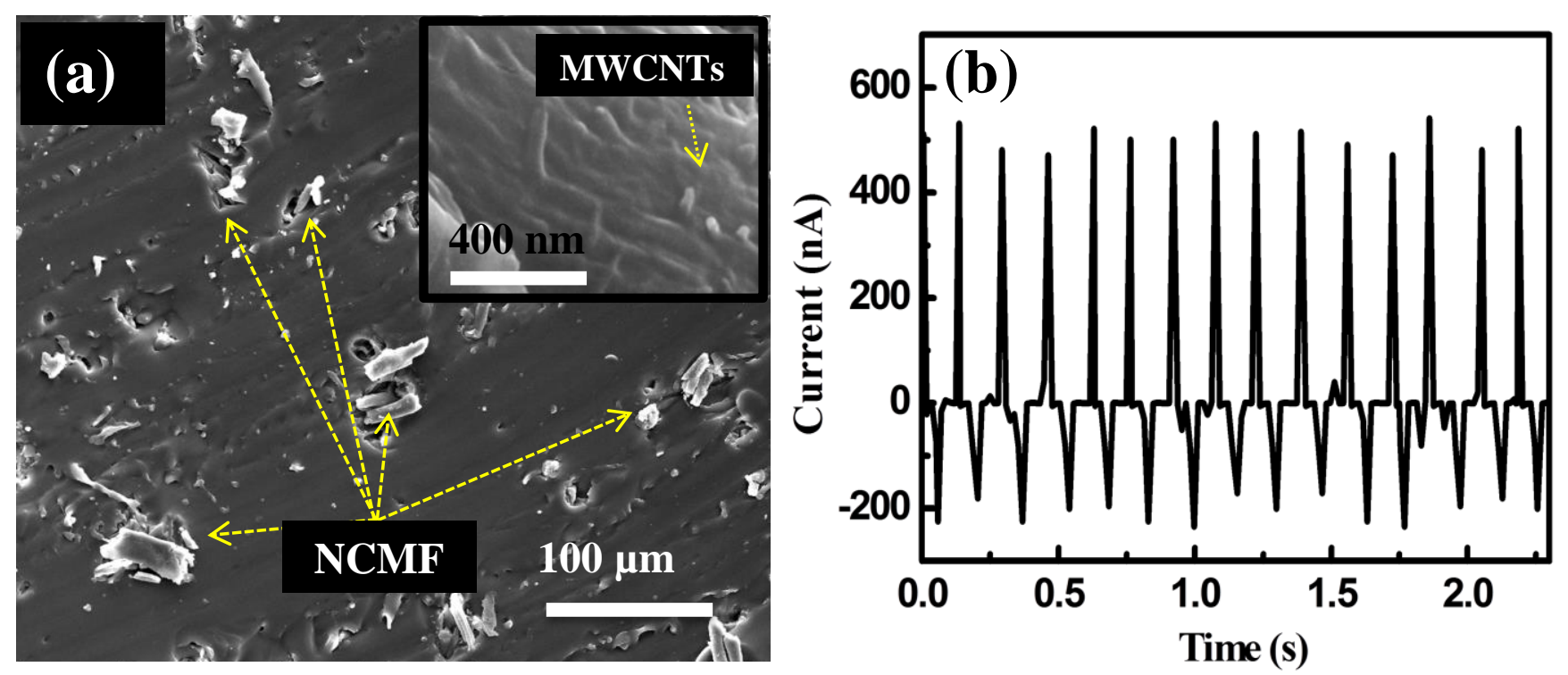

Figure S2. (a) The FE-SEM image of the PDMS-cellulose-MWCNTs composite film. The inset shows the MWCNTs in the composite film (b) Short circuit current from the HPG under repeating human hand punching of the stress amplitude of $40 \mathrm{kPa}$. 


\section{Text S2. Power Calculation.}

Power $(\mathrm{P})=\mathrm{VI}$

$=15 \mu \mathrm{W}$

Power density $=\frac{\text { Power }}{\text { Active area } \times \text { Thickness }}=9.09 \mu \mathrm{W} / \mathrm{cm}^{3}$

Here, $\mathrm{V}=30 \mathrm{~V}, \mathrm{I}=500 \mathrm{nA}$, active area $=33 \times 25 \mathrm{~mm}^{2}$, thickness $=2 \mathrm{~mm}$. 
Table S2: Comparison of the HPG performance with other reported data.

\begin{tabular}{|c|c|c|c|c|c|}
\hline $\begin{array}{l}\text { Piezoelectric } \\
\text { components }\end{array}$ & $\begin{array}{c}\text { Poling } \\
\text { voltage and } \\
\text { duration }\end{array}$ & $\begin{array}{l}\text { Sources/input } \\
\text { pressure or force }\end{array}$ & $\begin{array}{c}\text { Voltage } \\
\text { (V) }\end{array}$ & Current (I) & Power density \\
\hline Cellulose-ZnO ${ }^{\mathrm{S7}}$ & Not found & $\begin{array}{l}\text { Ultrasonic bath/Not } \\
\text { found }\end{array}$ & $80 \mathrm{mV}$ & $1.25 \mu \mathrm{A}$ & $50 \mathrm{nW} / \mathrm{cm}^{2}$ \\
\hline $\begin{array}{l}\mathrm{ZnO} \mathrm{NWs} / \\
\text { paper }^{88}\end{array}$ & Not found & $\begin{array}{l}\text { Not found /Not } \\
\text { found }\end{array}$ & $17 \mathrm{mV}$ & $400-520 \mathrm{pA}$ & $5 \times 10^{-3} \mu \mathrm{W} / \mathrm{cm}^{2}$ \\
\hline $\begin{array}{c}\mathrm{ZnO} \\
\mathrm{NWs} / \mathrm{PVDF}^{\mathrm{S} 9}\end{array}$ & $100 \mathrm{kV} / \mathrm{mm}$ & $\begin{array}{l}\text { Linear motor/Not } \\
\text { found }\end{array}$ & $0.2 \mathrm{~V}$ & $10 \mathrm{nA} / \mathrm{cm}^{2}$ & $2 \mu \mathrm{W} / \mathrm{cm}^{3}$ \\
\hline \multirow[t]{2}{*}{$\mathrm{BaTiO}_{3} \mathrm{NPs}^{\mathrm{s} 10}$} & $100 \mathrm{kV} / \mathrm{cm}$; & Bending stage/ & $3.2 \mathrm{~V}$ & $350 \mathrm{nA}$ & $0.26 \mu \mathrm{W} / \mathrm{cm}^{3}$ \\
\hline & $20 \mathrm{~h}$ & $57 \mathrm{kPa}$ & & & \\
\hline $\mathrm{ZnSnO}_{3}{ }^{\mathrm{S} 6}$ & Not Found & $\begin{array}{c}\text { Human finger press/ } \\
12 \mathrm{kPa}\end{array}$ & $40 \mathrm{~V}$ & $0.4 \mu \mathrm{A}$ & $10.8 \mu \mathrm{W} / \mathrm{cm}^{3}$ \\
\hline $\begin{array}{c}\mathrm{KNbO}_{3} \\
\text { Nanorod }^{\mathrm{S11}}\end{array}$ & $150 \mathrm{kV} ; 1 \mathrm{~h}$ & $\begin{array}{l}\text { Linear motor } / 0.38 \% \\
\text { strain and } 15.2 \% \mathrm{~s}^{-1} \\
\text { strain rate }\end{array}$ & $3.2 \mathrm{~V}$ & $67.5 \mathrm{nA}$ & $11.9 \mu \mathrm{W} / \mathrm{cm}^{3}$ \\
\hline $\begin{array}{c}\mathrm{KNbO}_{3} \\
\text { nanowires }\end{array}$ & $\begin{array}{c}5.0 \mathrm{kV} / \mathrm{mm} ; 1 \\
\mathrm{~h}\end{array}$ & $\begin{array}{c}\text { Bending tester/ a } \\
\text { strain and strain rate } \\
\text { of } 2.1 \% \text { and } \\
2.2 \% \mathrm{~s}^{-1}\end{array}$ & $10.5 \mathrm{~V}$ & $1.3 \mu \mathrm{A}$ & $42 \mu \mathrm{W} / \mathrm{cm}^{3}$ \\
\hline $\begin{array}{c}\mathrm{BaTiO}_{3} \\
\text { nanotubes }\end{array}$ & $\begin{array}{c}80 \mathrm{kV} / \mathrm{cm} ; 12 \\
\mathrm{~h}\end{array}$ & $\begin{array}{l}\text { Linear motor/ } \\
\qquad 1 \mathrm{MPa}\end{array}$ & $5.5 \mathrm{~V}$ & $350 \mathrm{nA}$ & $64 \mu \mathrm{W} / \mathrm{cm}^{3}$ \\
\hline KNN-LTS ${ }^{\text {S14 }}$ & $\underset{\mathrm{h}}{2 \mathrm{KV} / \mathrm{mm} ; 24}$ & $\begin{array}{c}\text { Mechanical tapping/ } \\
933 \mathrm{kPa}\end{array}$ & $53 \mathrm{~V}$ & $15 \mu \mathrm{A}$ & $115 \mu \mathrm{W} / \mathrm{cm}^{3}$ \\
\hline $\begin{array}{c}\text { NCMF } \\
\text { (present work) }\end{array}$ & Not Poled & $\begin{array}{c}\text { Human hand } \\
\text { punching/40kPa }\end{array}$ & $30 \mathrm{~V}$ & $500 \mathrm{nA}$ & $9 \mu \mathrm{W} / \mathrm{cm}^{3}$ \\
\hline
\end{tabular}




\section{Mechanism of high output parformance of the HPG:}

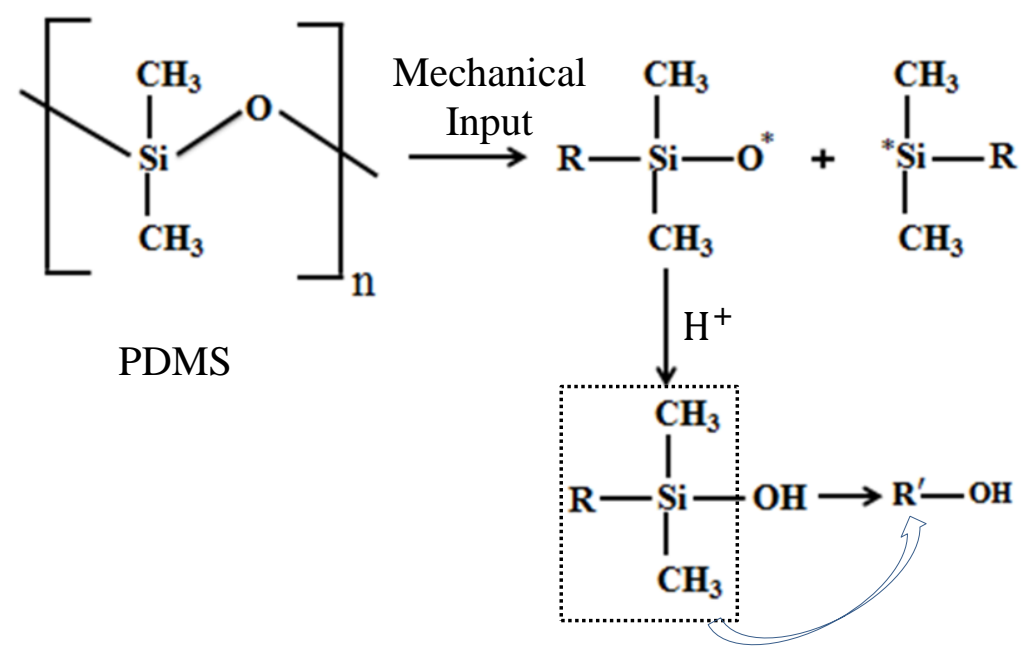

Figure S3. Schematic that illustrates the homolytic (leading to radical) chain breaking of PDMS upon mechanical input. ${ }^{\mathrm{S} 15}$ Reproduced with permission from reference $\mathrm{S} 15$. Copyright 2013 Royal Society of Chemistry.

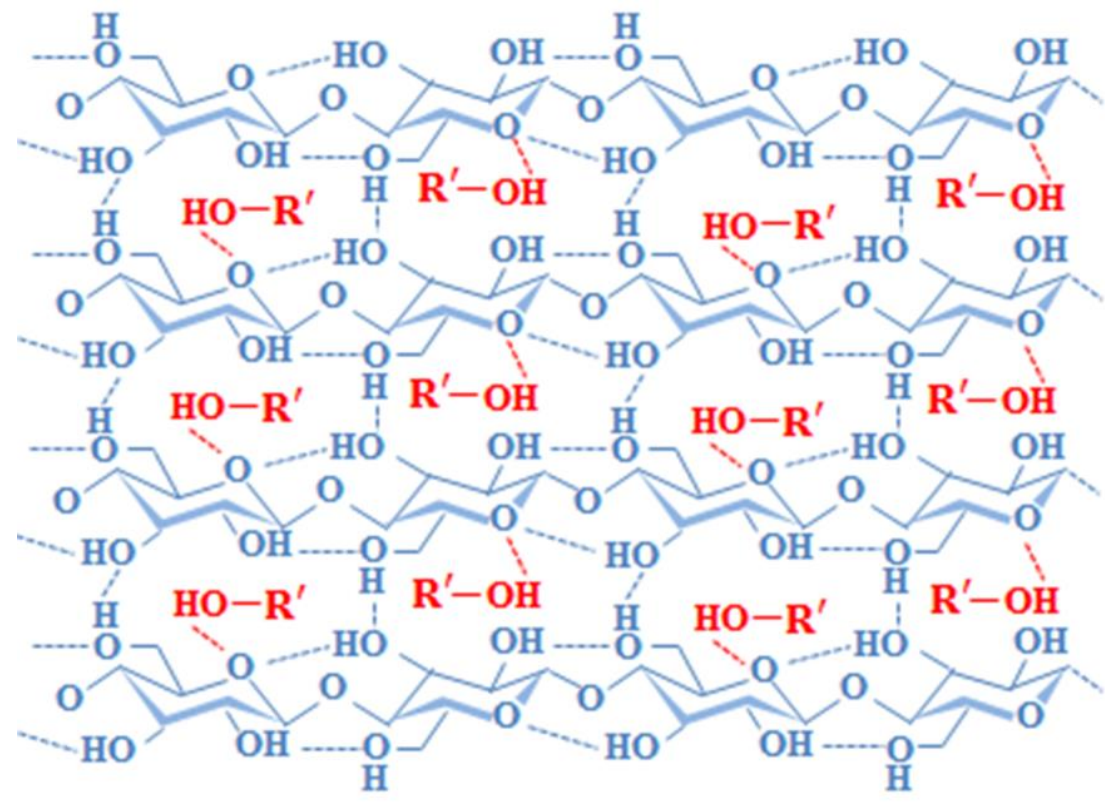

Figure S4. Schematic presentation of the structure of cellulose after the application of mechanical stress where $\mathrm{OH}$-group containing elements, produced from chain breaking of PDMS make hydrogen bonding with the oxygen atom of the glucose units. ${ }^{\mathrm{S} 15, \mathrm{~S} 16}$ Reproduced with permission from reference S15. Copyright 2013 Royal Society of Chemistry. 


\section{Text S3. Piezoelectric coefficient measurment.}

We have measured the piezoelectric coefficient $\left(\mathrm{d}_{33}\right)$ value of the hybrid composite film (which was used for fabricating HPG) using a $d_{33}$ meter (Piezotest, PM300) under the constant applied force of $0.5 \mathrm{~N}$ and frequency at $49 \mathrm{~Hz}$. We noticed that the value is lying between 8 to $15 \mathrm{pC} / \mathrm{N}$, which is probably attributed to the viscoelastic behaviour of the hybrid composite film. ${ }^{\text {S17, S18 }}$ The bond breaking of PDMS under mechanical stress may also be responsible for the variation of piezoelectric coefficient $\left(\mathrm{d}_{33}\right)$ in between 8-15 pC/N.

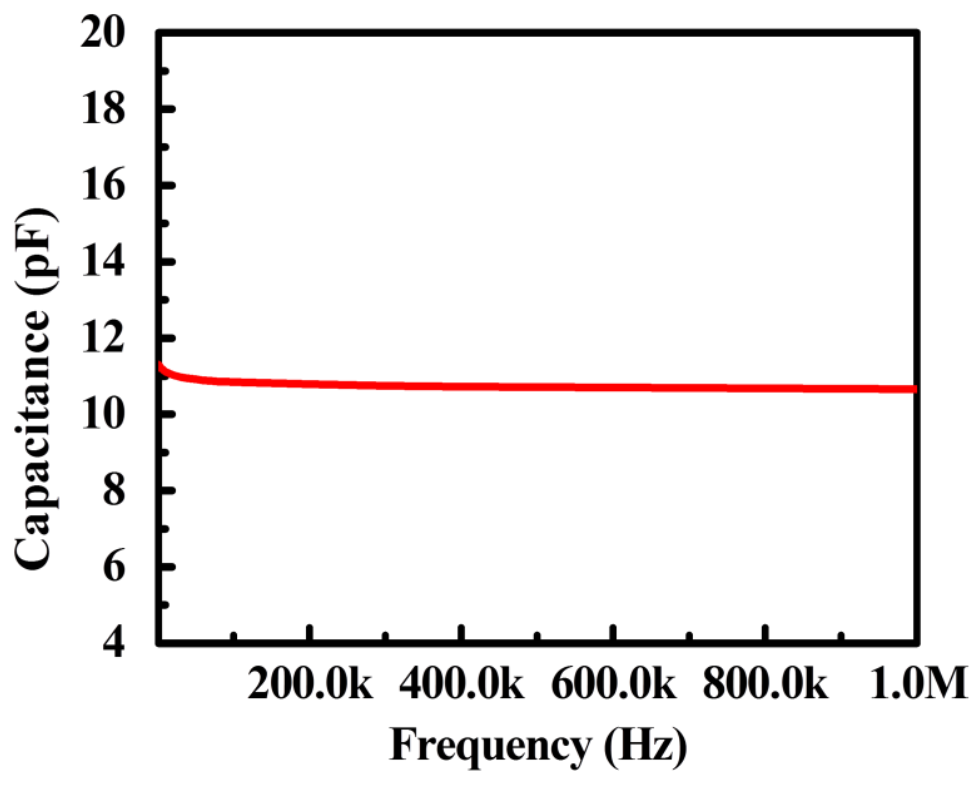

Figure S5. Capacitance versus frequency curve of the hybrid composite film, utilized for HPG fabrication.

To check the validity of the $d_{33}$ measurement, we have performed frequency dependence capacitance (shown in Supporting Information, Figure S5) measurement by impedance analyser. ${ }^{\text {S19 }}$ If we use the value of capacitance and measured value of $d_{33}$ (for example, 8 $\mathrm{pC} / \mathrm{N}$ and $15 \mathrm{pC} / \mathrm{N}$ ) then voltage output generated by our HGP is found to be $24 \mathrm{~V}$ and $45 \mathrm{~V}$ by using the following equation: ${ }^{\mathrm{S} 20}$

$\mathrm{V}=\mathrm{F} \times \mathrm{d}_{33} / \mathrm{C}$ 
Where, $\mathrm{F}$ is applied force and $\mathrm{C}$ is the capacitance.

Thus, we believed that our generated output voltage is very much consistent with the piezoelectric frame of references.

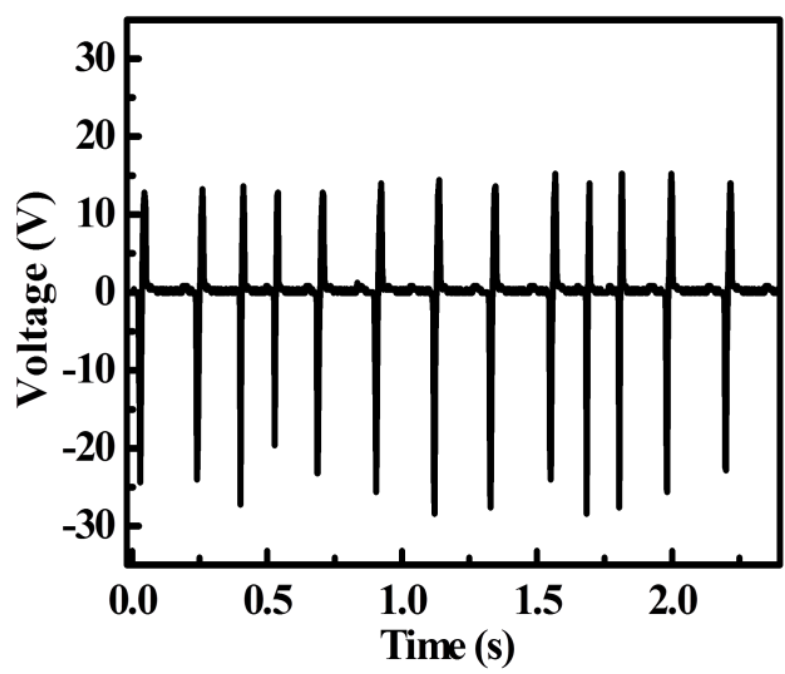

Figure S6. The open circuit voltage signals from the HPG generated in the reverse connection.
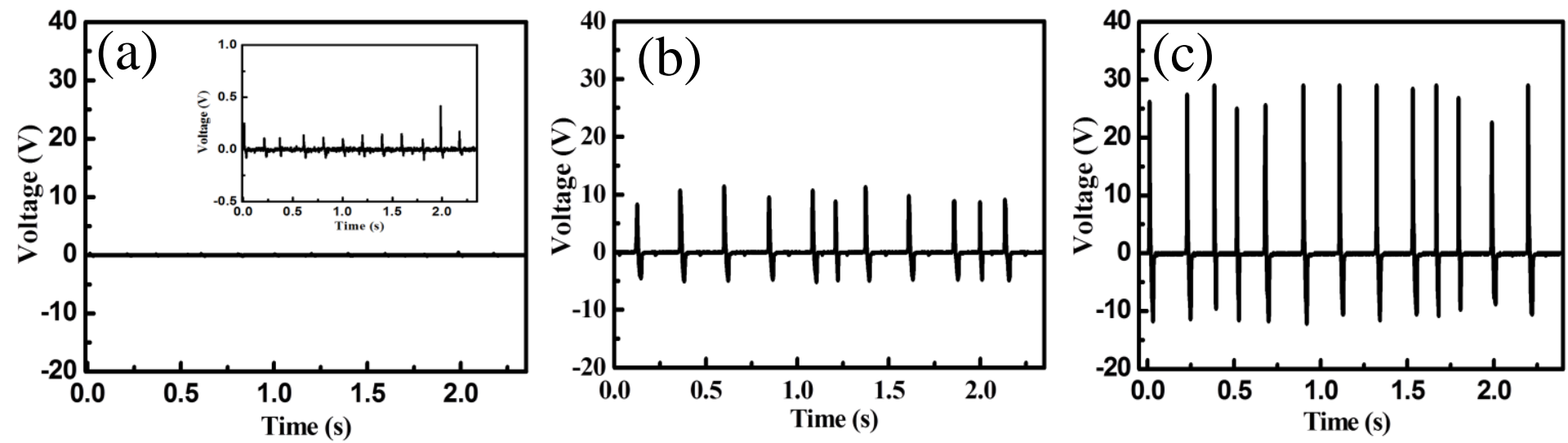

Figure S7. The open circuit voltage signals generated from HPG made with (a) PDMSMWCNTs (inset shows the enlarge view), (b) PDMS-NCMF, (c) PDMS-NCMF-MWCNTs. 

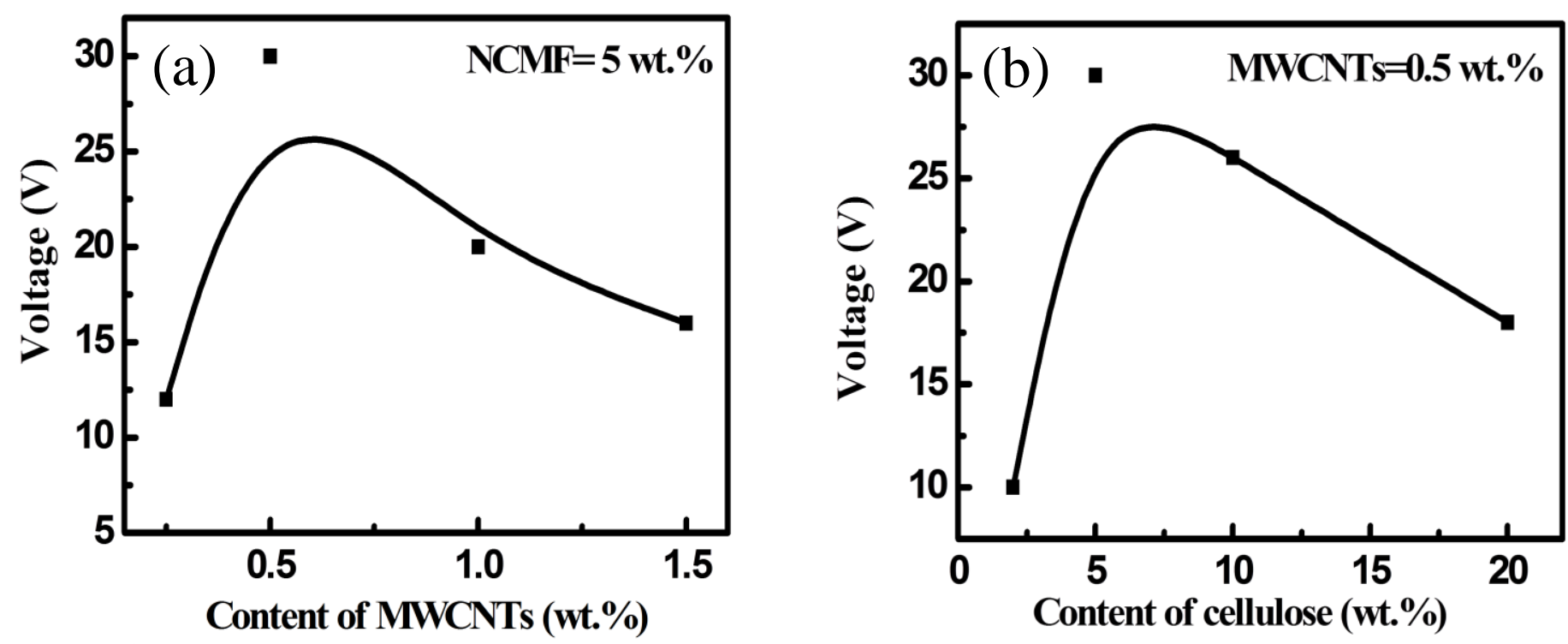

Figure S8. (a) The variation of output voltage from HPG as a function of MWCNT concentration for a fixed amount of $\operatorname{NCMF}(5 \mathrm{wt}$. \%). (b) The variation of output voltage from HPG as a function of NCMF concentration for a fixed amount of MWCNTs (0.5 wt. $\%)$. 


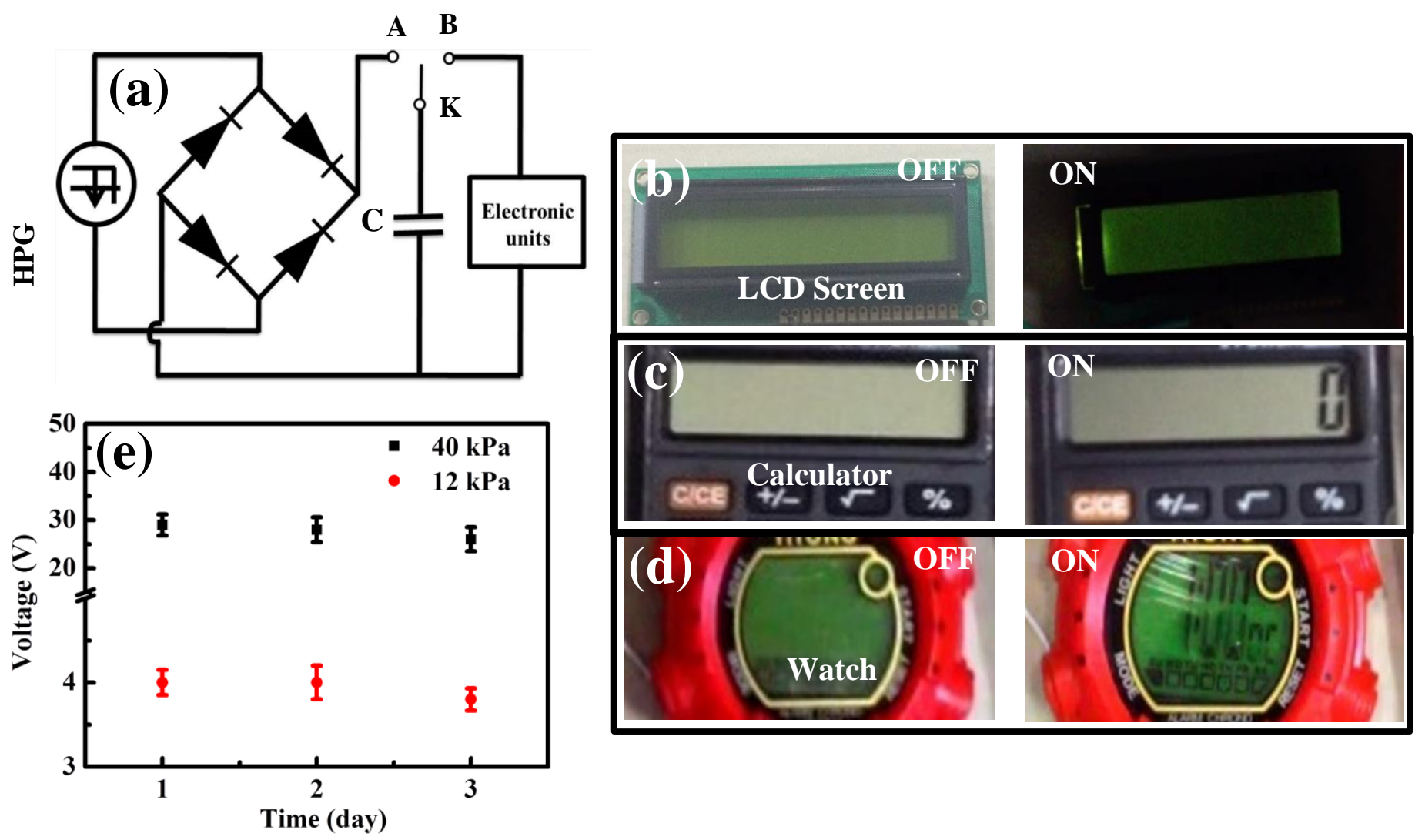

Figure S9. (a) A schematic of a circuit diagrams for capacitor charging and power up the electronic units (e.g., LCD screen, calculator and wrist watch). The AC voltage generated from the HPG is converted to DC voltage via the full wave rectifier and utilizes to charge up the capacitor (when the key " $\mathrm{K}$ " is connected to the point " $\mathrm{A}$ "). This charged capacitor then connect to an electronic unit to power up (when key " $\mathrm{K}$ " is connected to the point " $\mathrm{B}$ "). (b)-(d) Photograph of the Off and On conditions of the LCD screen, calculator and wrist watch respectively when these are powered up by charged capacitor. (e) The output voltages of the HPG under hand punching and pressure imparting probe with stress amplitude $40 \mathrm{kPa}$ and $\sim 12 \mathrm{kPa}$, respectively in three successive days after repeating imparting for 1500 s each day (shown in Figure S10) with pressure imparting probe (Freq 7 Hz, applied pressure 12 $\mathrm{kPa}$ ). The output voltage arises no significant change after 3 days. 

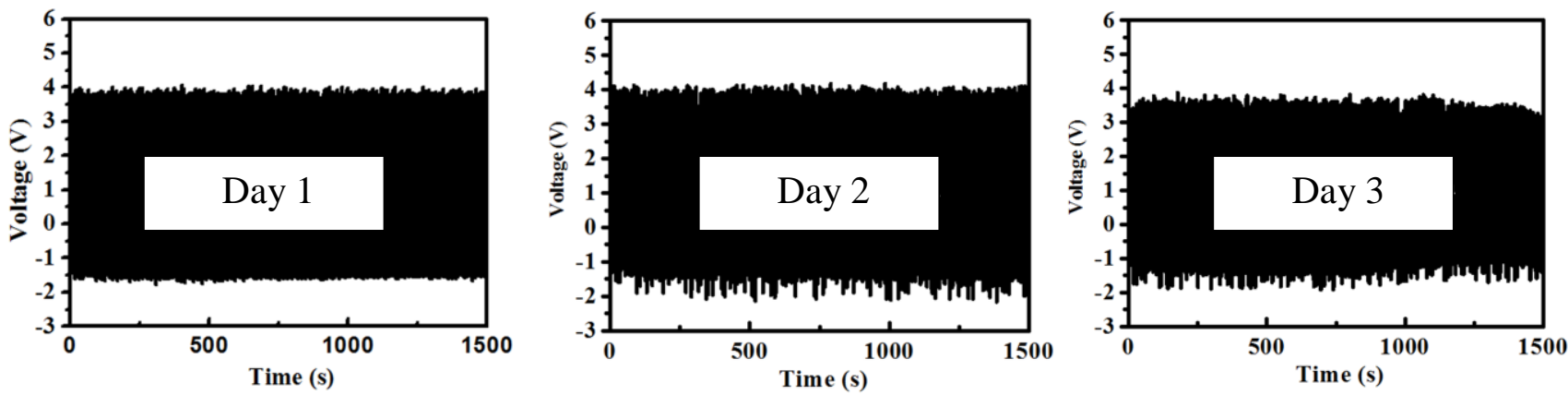

Figure S10. Stability of the HPG was tested under compressive stress amplitude of $12 \mathrm{kPa}$ by pressure imparting probe (Freq 7 Hz) at different days of operation (1500 second per day).

\section{REFERENCES}

(S1) Li, J.; Qiang, D.; Zhang, M.; Xiu, H.; Zhang, X. Joint Action of Ultrasonic and $\mathrm{Fe}^{3+}$ to Improve Selectivity of Acid Hydrolysis for Microcrystalline Cellulose. Carbohydr. Polym. 2015, 129, 44-49.

(S2) Kamphunthong, W.; Hornsby, P.; Sirisinha K. Isolation of Cellulose Nanofibers from Para Rubberwood and their Reinforcing Effect in Poly (vinyl alcohol) Composites. J. Appl. Polym. 2012, 125, 1642-1651.

(S3) Han, J.; Zhou, C.; Wu, Y.; Liu, F.; Wu, Q. Self-Assembling Behaviour of Cellulose Nanoparticles during Freeze-Drying: Effect of Suspension Concentration, Particle Size, Crystal Structure, and Surface Charge. Biomacromolecules 2013, 14, 1529-1540.

(S4) Kavkler, K.; Demšar, A. Application of FTIR and Raman Spectroscopy to Qualitative Analysis of Structural Changes in Cellulosic Fibres. Tekstilec 2012, 55, 19-31.

(S5) Hou, C.; Huang, T.; Wang, H.; Yu, H.; Zhang, Q.; Li, Y. A Strong and Stretchable SelfHealing Film with Self-Activated Pressure Sensitivity for Potential Artificial Skin Applications. Sci. Rep. 2013, DOI:10.1038/srep03138. 
(S6) Alam, M. M.; Ghosh, S. K.; Sultana, A.; Mandal, D. Lead-free $\mathrm{ZnSnO}_{3} / \mathrm{MWCNTs}^{-}$ Based Self-poled Flexible Hybrid Nanogenerator for Piezoelectric Power Generation. Nanotechnology 2015, 26, 165403-165409.

(S7) Kumar, A.; Gullapalli, H.; Balakrishnan, K.; Botello-Mendez , A.; Vajtai, R.; Terrones, M. Ajayan, P. M. Flexible ZnO-Cellulose Nanocomposite for Multisource Energy Conversion. Small 2011, 7, 2173-2178.

(S8) Liao, Q.; Zhang, Z.; Zhang, X.; Mohr, M.; Zhang, Y.; Fecht, H.-J. Flexible Piezoelectric Nanogenerators Based on Fiber/ZnO Nanowires/ Paper Hybrid Structure for Energy Harvesting. Nano Res. 2014, 7, 917-930.

(S9) Lee, M.; Chen, C.-Y.; Wang, S.; Cha, S. N.; Park, Y. J.; Kim, J. M.; Chou, L.-J.; Wang, Z. L. A Hybrid Piezoelectric Structure for Wearable Nanogenerators. Adv. Mater. 2012, 24, $1759-1764$.

(S10) Park, K.-I.; Lee, M.; Liu, Y.; Moon, S.; Hwang, G.-T.; Zhu, G.; Kim, J. E.; Kim, S. O.; Kim, D. K.; Wang, Z. L.; Lee, K. J. Flexible Nanocomposite Generator Made of $\mathrm{BaTiO}_{3}$ Nanoparticles and Graphitic Carbons. Adv. Mater. 2012, 24, 2999-3004.

(S11) Jung, J. H.; Chen, C.-Y.; Yun, B. K.; Lee, N.; Zhou, Y.; Jo, W.; Chou, L.-J.; Wang, Z. L. Lead-free $\mathrm{KNbO}_{3}$ Ferroelectric Nanorod based Flexible Nanogenerators and Capacitors. Nanotechnology 2012, 23, 375401-375407.

(S12) Joung, M.-R.; Xu, H.; Seo, I.-T.; Kim, D.-H.; Hur, J.; Nahm, S.; Kang, C.-Y.; Yoon, S.-J.; Park, H.-M. Piezoelectric Nanogenerators Synthesized using $\mathrm{KNbO}_{3}$ Nanowires with Various Crystal Structures. J. Mater. Chem. A 2014, 2, 18547-18553.

(S13) Lin, Z.-H.; Yang, Y.; Wu, J. M.; Liu, Y.; Zhang, F.; Wang, Z. L. BaTiO 3 NanotubesBased Flexible and Transparent Nanogenerators. J. Phys. Chem. Lett. 2012, 3, 3599-3604. 
(S14) Xue, Q.-T.; Wang, Z.; Tian, H.; Huan, Y.; Xie, Q.-Y.; Yang, Y.; Xie, D.; Li, C.; Shu, Y.; Wang, X-H.; Ren, T.-L. A Record Flexible Piezoelectric KNN Ultrafine-Grained Nanopowder-Based Nanogenerator. AIP Adv. 2015, 5, 017102-017108.

(S15) Baytekin, B.; Baytekin H. T.; Grzybowski, B. A. Retrieving and Converting Energy From Polymers: Deployable Technologies and Emerging Concepts. Energy Environ. Sci. 2013, 6, 3467-3482.

(S16) Kondo,T.; Sawatari, C.; Manley, R. S. J.; Gray, D. G. Characterization of Hydrogen Bonding in Cellulose-Synthetic Polymer Blend Systems with Regioselectively Substituted Methylcellulose. Macromolecules 1994, 27, 210-215.

(S17) Babu, I.; Meis, N.; de With, G. Measuring the Direct Piezoelectric Charge Coefficient for Polymer Matrix Composites. Polymer Testing 2014, 40, 286-289.

(S18) Sharma, S. K.; Gaur, H.; Kulkarni, M.; Patil, G.; Bhattacharya, B.; Sharma, A. PZTPDMS Composite for Active Damping of Vibrations. Compos. Sci. Technol. 2013, 77, 4251.

(S19) Al-Ahmad, M.; Plana, R. A Novel Method for PZT Thin Film Piezoelectric Coefficients Determination Using Conventional Impedance Analyzer, Proce. 37th European Microwave Conf., Oct., 2007, Germany.

(S20) Mahadeva, S. K.; Walus, K.; Stoeber, B. Piezoelectric Paper Fabricated via Nanostructured Barium Titanate Functionalization of Wood Cellulose Fibers. ACS Appl. Mater. Interfaces 2014, 6, 7547-7553.

Video 1- Power up the LED

Video 2- Power up the LCD screen 